УДК 621.291:396

\title{
НЕЙРОСЕТЕВЫЕ ФУНКЦИОНАЛЬНЫЕ МОДЕЛИ И АЛГОРИТМЫ ПРЕОБРАЗОВАНИЯ ИНФОРМАЦИИ ДЛЯ СОЗДАНИЯ ЦИФРОВЫХ ВОДЯНЫХ ЗНАКОВ
}

\author{
СИРОТА А. А., ДРЮЧЕНКО М. А., МИТРОФАНОВА Е. Ю. \\ Воронежский государственньй университет, \\ Россия, Воронеж, 394006, Университетская пл., д. 1
}

\begin{abstract}
Аннотация. Рассмотрены нейросетевые функциональные модели и алгоритмы преобразования информации, обеспечивающие стеганографическое кодирование сообщений в форме цифровых водяных знаков (ЦВ3) в произвольные объекты - контейнеры (цифровые изображения) и их последующее декодирование при минимальных уровнях искажения контейнера. В основе подхода лежит теоретическое обоснование возможности построения гетероассоциативных и автоассоциативных сжимающих отображений фрагментов контейнера с использованием искусственных нейронных сетей прямого распространения. Представлены зависимости для показателей качества ЦВ3, описывающие уровень искажения контейнера, а также вероятность ошибки при декодировании двоичной последовательности ЦВЗ, полученные для моделей изображений в виде случайных полей, а также для реальных изображений
\end{abstract}

Ключевые слова: сжатие информации; нейронная сеть; обработка изображений; стеганография; цифровые водяные знаки

\section{ВВЕДЕНИЕ}

Одним из перспективных направлений развития систем обработки сигналов и изображений является применение методов компьютерной стеганографии для создания цифровых водяных знаков (ЦВ3), которые используются для защиты авторских прав объектов, представленных в цифровом виде, создания радиочастотных меток повышенной скрытности, хранения конфиденциальной информации, а также скрытной передачи данных в системах телекоммуникаций. В связи с этим наибольшее распространение получили методы, основан- ные на использовании свойств избыточности хранимой или передаваемой аудио- и видеоинформации.

Для эффективного применения технологий на основе создания стеганографически скрытых сообщений, в частности технологий ЦВ3, необходимо выполнить ряд взаимосвязанных требований: обеспечить аудио- и визуальную незаметность сообщений, сохранить исходное качество контейнера, обеспечить высокую достоверность извлечения сообщения и необходимую пропускную способность канала передачи сообщения, содержащегося в ЦВЗ. Указанные требования не реализуются в пол-

* Исследование выполнено при финансовой поддержке РФФИ в рамках научного проекта № 13-01-97507 р_центр_а. 